\title{
Open partial nephrectomy: current review
}

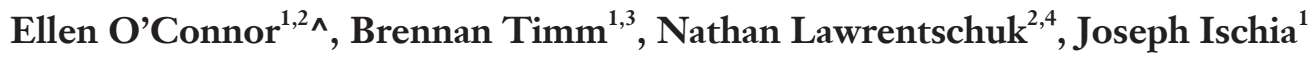 \\ ${ }^{1}$ Department of Surgery, University of Melbourne, Austin Health, Heidelberg, Australia; ${ }^{2}$ Department of Surgical Oncology, Peter MacCallum \\ Cancer Centre, Melbourne, Australia; ${ }^{3}$ North Eastern Urology, Heidelberg, Australia; ${ }^{4}$ Department of Urology, The Royal Melbourne Hospital, \\ Melbourne, Australia \\ Contributions: (I) Conception and design: E O'Connor, J Ischia; (II) Administrative support: E O'Connor, B Timm; (III) Provision of study materials \\ or patients: E O'Connor, B Timm; (IV) Collection and assembly of data: E O'Connor, B Timm; (V) Data analysis and interpretation: E O'Connor, B \\ Timm; (VI) Manuscript writing: All authors; (VII) Final approval of manuscript: All authors. \\ Correspondence to: Dr. Ellen O'Connor. Department of Surgery, University of Melbourne, Austin Health, Level 8 Harold Stokes Building, 145 Studley \\ Rd., Heidelberg, VIC 3084, Australia. Email: Ellen.O’Connor@austin.org.au.
}

\begin{abstract}
Partial nephrectomy $(\mathrm{PN})$ is increasingly considered the gold standard treatment for localized renal cell carcinomas (RCCs) where technically feasible. The advantage of nephron-sparing surgery lies in preservation of parenchyma and hence renal function. However, this advantage is counterbalanced with increased surgical risk. In recent years with the popularization of minimally invasive partial nephrectomy (laparoscopic and robotic), the contemporary role of open PN (OPN) has changed. OPN has several advantages, particularly in complex patients such as those with a solitary kidney, multi-focal tumors, and significant surgical history, as well as providing improved application of renoprotective measures. As such, it is a technique that remains relevant in current urology practice. In this article we discuss the evidence, indications, operative considerations and surgical technique, along with the role of OPN in contemporary nephron-sparing surgery.
\end{abstract}

Keywords: Renal neoplasm; urological surgical procedures; minimally invasive surgical procedures; nephron; organ preservation; complications

Submitted Jan 21, 2020. Accepted for publication May 21, 2020.

doi: $10.21037 /$ tau-20-474

View this article at: http://dx.doi.org/10.21037/tau-20-474

\section{Introduction}

Partial nephrectomy (PN) has emerged as the widely recommended treatment for small renal tumors, clinical $\mathrm{T} 1 \mathrm{a}-\mathrm{b}$, following publication of favorable oncological and functional outcomes over radical nephrectomy (RN) (1). Open PN (OPN) was first performed by Spencer Wells in 1884, when one-third of a kidney was inadvertently removed with the excision of a peri-renal fibroadenoma (2). It was 3 years later when Czerny was credited with performing the first deliberate OPN for angiosarcoma $(2,3)$. Advances to nephron-sparing surgery were largely made in the 1960s with increased understanding of the segmental arterial supply of the kidney and the utilization of renal hypothermia. Modern medical imaging has further revolutionized the role of $\mathrm{PN}$ due to the increasing volume of incidentally diagnosed small renal masses.

As urology has embraced the gradual shift from open to minimally invasive surgery (MIS), $\mathrm{PN}$ is being completed more often by laparoscopic and robotic methods (4). This has led to significant reassessment of the role of OPN. An increasing desire for nephron-sparing surgery has enabled surgeons to test the boundaries with more challenging clinical scenarios and complex tumors. Although there is debate over the role of OPN in an era of MIS, current international guidelines cite the priority being renal preservation regardless of approach $(5,6)$.

^ ORCID: 0000-0001-8576-586X. 
Table 1 RCC T staging and proportion at diagnosis

\begin{tabular}{lll}
\hline Staging score & Description $(6)$ & Incidence at diagnosis (\%) (7-9) \\
\hline T1a & Tumor $<4 \mathrm{~cm}$ size, limited to kidney & \\
T1b & Tumor $>4 \mathrm{~cm}$, but $<7 \mathrm{~cm}$, limited to kidney \\
T2 & Tumor $\geq 7 \mathrm{~cm}$, limited to kidney & $10-23.3$ \\
T3 & Tumor extends into major veins or perinephric tissues, but not & $8-13.9$ \\
& beyond Gerota fascia & $11-18.7$ \\
T4 & Tumor extends beyond Gerota fascia & 11 \\
\hline
\end{tabular}

RCC, renal cell carcinoma.

Table 2 Indications and contraindications for OPN

\begin{tabular}{ll}
\hline Indications & Description \\
Absolute & Single anatomical or functional kidney \\
& Bilateral renal masses \\
Relative & Chronic renal impairment \\
& Hereditary RCC syndromes \\
Elective & Localized unilateral RCC (healthy \\
& contralateral kidney) \\
Contraindications & \\
& Metastatic or locally advanced disease \\
& Insufficient volume of remaining \\
& parenchyma \\
& Renal vein thrombosis \\
& Uncorrected bleeding disorder \\
& Non-reversible anticoagulation \\
& Significant cardiopulmonary compromise \\
& Cl time $>45$ minutes \\
& Tumor encasement of renal pedicle \\
Relative & Diffuse tumor invasion of central collecting \\
& system \\
\hline
\end{tabular}

OPN, open partial nephrectomy; RCC, renal cell carcinoma; $\mathrm{Cl}$, cold ischemia.

\section{Indications for PN}

Owing primarily to widespread use of cross-sectional imaging such as computerized tomography (CT) and ultrasound, incidence of primary renal cell carcinoma (RCC) has increased globally. With the vast majority of small renal masses being diagnosed incidentally, close to $50 \%$ of renal neoplasms are now stage T1a at diagnosis (Table 1) $(7,10,11)$. This is associated with a corresponding improvement in mortality rates $(11,12)$. The associated stage migration towards earlier stage disease has led to a desire for surgery with maximal preservation of renal parenchyma and nephrons. It is now widely acknowledged that nephronsparing surgery has the ability to better preserve longterm renal function and therefore reduce subsequent risk of cardiovascular and metabolic disorders (13). Given excellent long-term cancer survival outcomes in patients undergoing PN $[85-96 \%$ cancer-specific survival at 10-year after surgery (12)], these functional outcomes are significant.

While PN was initially reserved for cases with a contraindication to $\mathrm{RN}$, such as solitary kidney, chronic kidney disease (CKD) and multi-focal or bilateral tumors, it has now become the surgical gold standard for all small renal tumors when technically feasible. Current guidelines from both American Urological Association (AUA) and European Association of Urology (EAU) recommend $\mathrm{PN}$ for all cT1a-b tumors $(5,6)$. This change in guideline recommendations has come following the publication of multiple retrospective studies and one prospective randomized control trial (RCT) by Van Poppel et al. demonstrating that $\mathrm{PN}$ is not inferior to $\mathrm{RN}$ for clinically T1a-b renal tumors $(1,14)$. PN can additionally be used in the management of benign renal pathology such as removal of benign tumors (angiomyolipoma and oncocytoma), infected calyceal diverticula, segmental traumatic and irreversible renal injury. Indications and contraindications for $\mathrm{PN}$ are outlined in Table 2.

\section{Open versus minimally invasive $P N$}

To date, good quality direct comparisons between OPN and minimally-invasive $\mathrm{PN}$ techniques are scarce. Many studies are limited by retrospective design, incomplete data series and lack of detail regarding tumor complexity. It is recognized that minimally invasive options provide 
Table 3 Overview of anatomical classification systems RENAL and PADUA

\begin{tabular}{|c|c|c|}
\hline Variables & RENAL nephrometry score (21) & PADUA score (22) \\
\hline Maximal tumor diameter & 1 pt: $\leq 4 \mathrm{~cm} ; 2$ pts: $>4 \mathrm{~cm}$ but $<7 \mathrm{~cm} ; 3$ pts: $\geq 7 \mathrm{~cm}$ & 1 pt: $\leq 4 \mathrm{~cm} ; 2$ pts: $>4 \mathrm{~cm}$ but $<7 \mathrm{~cm} ; 3$ pts: $\geq 7 \mathrm{~cm}$ \\
\hline Exophytic/endophytic & 1 pt: $\geq 50 \%$; 2 pts: $<50 \%$; 3 pts: entirely endophytic & 1 pt: $\geq 50 \%$; 2 pts: $<50 \%$; 3 pts: endophytic \\
\hline Renal sinus & $\mathrm{N} / \mathrm{A}$ & 1 pt: not involved; 2 pts: involved \\
\hline Anterior/posterior & Mass assigned $a, p$, or $x$ & Mass assigned a or $p$ \\
\hline Renal rim location & $\mathrm{N} / \mathrm{A}$ & 1 pt: lateral; 2 pts: medial \\
\hline
\end{tabular}

pt, point.

an advantage regarding perioperative morbidity. However, oncological and functional results remain comparable $(15,16)$. Bravi et al. undertook a prospective observational review comparing open, robotic and laparoscopic PN perioperative outcomes in 2,331 patients where OPN was found to be associated with shorter ischemia time when compared to both robotic and laparoscopic approaches (17). The authors postulated several possible explanations for this finding including lack of haptic feedback, compromised vision and surgical team experience. In terms of perioperative outcomes such as length of stay and blood loss however, the robotic approach proved superior. Studies comparing more complex and larger (T2) tumors have further tried to characterize the role of robotic $\mathrm{PN}$ over OPN. Once again conceding the limitations of retrospective and observational study designs, the perioperative, functional and oncological outcomes appear to be equivalent $(18,19)$. Acknowledging the well documented peri-operative advantages to minimally invasive $\mathrm{PN}$, there is no evidence to suggest that OPN should be considered inferior $(5,6)$. This is especially pertinent in institutions which may lack robotic technology or surgical expertise in minimally invasive techniques.

\section{Pre-operative considerations}

Important patient factors which need to be assessed preoperatively include age, baseline renal function and medical co-morbidities. All patients should undergo routine blood tests including electrolytes, renal- and liver-function, coagulation profile and group and hold. Antiplatelet and anticoagulant medication should be withheld based on product pharmacodynamics and patient factors, and patients with uncorrected coagulopathies should be carefully considered and undergo hematology consultation. Prior surgical history is important, especially in the event of suspected adhesions or loss of tissue planes, this is especially pertinent in the event of re-operation on a kidney for tumor recurrence or positive surgical margins. In these situations, open surgery may be a preferred approach over laparoscopic or robotic techniques due to increased technical difficulty (20).

Tumor factors which require careful pre-operative consideration include tumor staging, location, size and depth. Adequate cross-sectional imaging is imperative in assessing tumor complexity and surrounding anatomical relations when deciding to perform an OPN. Objective anatomical classification systems have been developed to standardize the description of renal tumors and assist in patient and surgical technique selection. These includes the C-index, RENAL nephrometry score and Preoperative Aspects and Dimensions Used for an Anatomical (PADUA) classification system amongst others (Table 3) (21-23). Use of these systems is helpful for objective decision making and comparison between treatment modalities. Renal scintigraphy may be necessary pre-operatively to evaluate split renal function. In a tumor containing kidney that is poorly functioning, $\mathrm{RN}$ may be the preferred option provided the contralateral kidney is healthy.

Patient specific anatomical variation has an important role regarding planning for nephron-sparing surgery. Given the importance of sufficient hilar access, preoperative imaging needs to adequately identify the renal artery and vein as well as any accessory or aberrant vessels. Conceptualization of the tumor location is key to assisting intra-operative resection and ensure the tumor is excised in its entirety without sacrificing excess normal renal parenchyma. Three-dimensional reconstruction and 


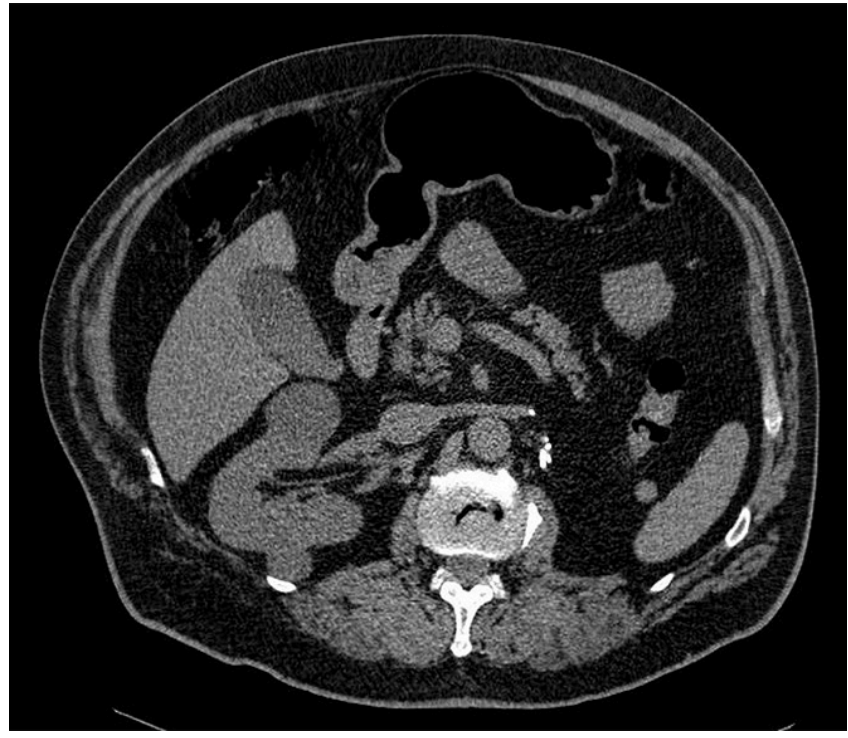

Figure 1 Axial CT demonstrating a right renal mass in a patient who has previously undergone left nephrectomy and right PN for RCC. Following successful OPN with renal hypothermia, eGFR stabilized to $45 \mathrm{~mL} / \mathrm{min} / 1.73 \mathrm{~m}^{2}$ post-operatively. CT, computerized tomography; $\mathrm{PN}$, partial nephrectomy; OPN, open partial nephrectomy; RCC, renal cell carcinoma.

Table 4 Considerations favoring OPN over minimally invasive PN

Prior renal surgery

High tumor complexity or multiple tumors

Solitary kidney

CKD

Expected prolonged ischemic time

Extracorporeal surgery

Lack of minimally-invasive surgical expertise

Lack of equipment required for minimally-invasive PN (e.g., robotic equipment, laparoscopic ultrasound)

OPN, open partial nephrectomy; CKD, chronic kidney disease.

printing has been developed to assist with this process at some institutions, particularly for hilar or completely intraparenchymal tumors (24). A particularly difficult intraoperative finding in $\mathrm{PN}$ is that of adherent perinephric fat. This so-called "toxic fat" introduces an added challenge when it comes to identification and isolation of the tumor. While few surgeons would normally plan for this factor pre-operatively, recent studies have proposed methods to identify this occurrence before surgery and the open surgical technique may be preferable to minimally invasive in these instances $(25,26)$.

The above pre-operative considerations are made even more essential in the context of the complex urological patient. Solitary kidney, bilateral tumors and familial RCC pose unique treatment dilemmas, some of the few instances where $\mathrm{PN}$ is an absolute indication (Figure 1). With regard to recurrent or metachronous tumors in patients with hereditary forms of RCC, such as von Hippel-Lindau disease, repeat salvage $\mathrm{PN}$ has been shown to provide adequate oncological outcomes whilst avoiding dialysis in this younger demographic of patients $(27,28)$. Patients with CKD are more susceptible to renal ischemia than those with healthy kidneys (29). Preservation of healthy renal parenchyma in these situations is imperative and therefore the surgical approach with the shortest ischemia time and minimal excision of normal parenchyma is paramount thereby favoring OPN. A list of considerations which may favor OPN over minimally-invasive PN are outlined in Table 4.

Percutaneous renal mass biopsy (RMB) is typically not necessary prior to $\mathrm{PN}$ owing to improved diagnostic accuracy of medical imaging and concern regarding nondiagnostic rate of $14 \%$ and limited negative predictive value $(70 \%)(5)$. Its primary recommended role is the diagnosis of indeterminate renal masses planned for non-surgical management or where differentials are concerning for inflammatory, infectious or metastatic disease (5). Despite this, a recent study has demonstrated that routine RMB does reduce surgery for benign tumor which is relevant as up to $30 \%$ of small renal masses are found to be benign on histological examination (30). Routine use of RMB in the United States appears to be increasing (15.3\%), however ultimately RMB is not currently indicated when it is unlikely to change management (31).

\section{Surgical technique for open partial nephrectomy}

\section{Positioning}

Following induction of anesthesia, intubation and insertion of indwelling catheter for urinary output monitoring, careful attention is made to patient positioning to allow adequate exposure to the retroperitoneum. The patient is positioned in the lateral decubitus position with the flank overlying the break in the table to allow for the table to be flexed to open the space between the costal margin and iliac crest. Careful attention to possible high-pressure areas including the axilla (risk to brachial plexus), the bottom hip 
(pressure sore) and the forearms (radial or ulnar nerves) are warranted while providing adequate anesthetic access and insuring the patient is well secured to the table.

\section{Surgical approacb}

A surgical approach which provides good exposure to upper and lower poles of the kidney, the tumor and renal hilum is necessary to avoid intra-operative complications. A traditional or large flank incision is most often done superior to the $12^{\text {th }}$ rib as it offers the opportunity to operate within the retroperitoneum avoiding intraperitoneal structures. This approach is often described in coordination with or without resection of the distal third of the $11^{\text {th }}$ or $12^{\text {th }}$ rib $(32,33)$. As an alternative, cases of mini OPN where an $8-10 \mathrm{~cm}$ incision is made superior to the $11^{\text {th }} \mathrm{rib}$ have been reported by Diblasio et al. and Wang et al. and found to have equivocal oncologic outcomes with fewer wound complications and a better cosmetic result $(34,35)$. The incision is made with care to avoid the intercostal neurovascular bundles which lie just below the rib above. The latissimus dorsi, external and obliques are transected while the transversus abdominis is split in the direction of its fibers. The transversalis fascia is broached by sharp dissection and remaining extra-peritoneal by pushing the peritoneum anteriorly. If operating above the $11^{\text {th }}$ rib, care should be taken to avoid the costodiaphragmatic recess and pleural reflections (34). In the event of previous flank incision, failed thermoablation or larger complex renal masses, a transperitoneal approach by anterior subcostal, midline or Mercedes Benz incision is preferred (36). Finally, there is a move away from flank incisions in some regions due to short and long-term morbidity (e.g., bulging) and thus other incisions such as anterior sub-costal or roof-top, even if infra-peritoneal, may be preferred $(36,37)$.

Best exposure is obtained through the use of some form of self-retractor with cephalad and caudal retraction between the ribs (dependent on where incision has been made) (38). A mix of blunt and sharp dissection to develop the retroperitoneal space with views to rotate the kidney medially for access to the renal pedicle. The plane between Gerota's fascia, the quadratus lumborum and psoas is developed by blunt dissection clipping and dividing any perforating blood vessels arising from the body wall. Dependent on surgical site, either the descending colon or the right colon/duodenum must be retracted medially. Further mobilization of the kidney from the retroperitoneum may be required to gain access to the renal hilum.

Identification of the hilar structures is paramount to renal viability and positive surgical outcomes in OPN (32). If there is difficulty finding the hilum due to factors such as size and fat content of the abdomen, isolation of the ureter at the lower pole of the kidney can act as a guide to its origin and aid identification of the renal artery and vein. Branches of the renal vein such as the lumbar, adrenal and gonadal may need to be clipped and ligated to facilitate access to the renal artery. At this stage both vessels should be separately isolated and we prefer to identify with by vessel loops of differing colors. Once the hilum has been successfully isolated, identification of the renal mass by texture, visually and ultrasound is required. While ultrasound may not be required for every case, our preference is to use it for every case so that you are wellpractized in its use for the difficult cases when required. De-fatting of a $2-5 \mathrm{~mm}$ margin surrounding the mass is advocated while surveying for unsuspected satellite tumor which may not have been detected on preoperative imaging $(34,39)$. When comfortable that a reasonable margin of resection can be attained without obstruction from other intraabdominal structures, attention can be turned to control of the renal blood supply.

\section{Ischemia}

Control of renal vessels is paramount for several reasons: to reduce excessive blood loss, to improve vision at resection as to avoid incomplete tumor resection, and reduction of renal turgor which allows for a more easily palpable mass in endophytic lesions (40). The renal vessels can be controlled by several methods utilizing either a bulldog clamp, vascular clamp, or finger/tourniquet compression of the adjacent parenchyma. The choice to control the artery and vein, the artery alone or in select cases, control of a segmental branch of the renal artery may reduce global renal ischemia $(41,42)$. Segmental branch control, anatomy permitting, involves clamping of a distal renal artery branch supplying the region of the tumor without impacting perfusion to the remaining normal parenchyma throughout the resection.

Off-clamp PN and parenchymal compression are both novel techniques being utilized which aim to avoid hilar clamping entirely (43). Regional ischemia by way of a parenchymal clamp or tourniquet may be feasible when the anatomy allows, particularly in the case of tumors in polar locations. Although off-clamp surgery provides the benefit 


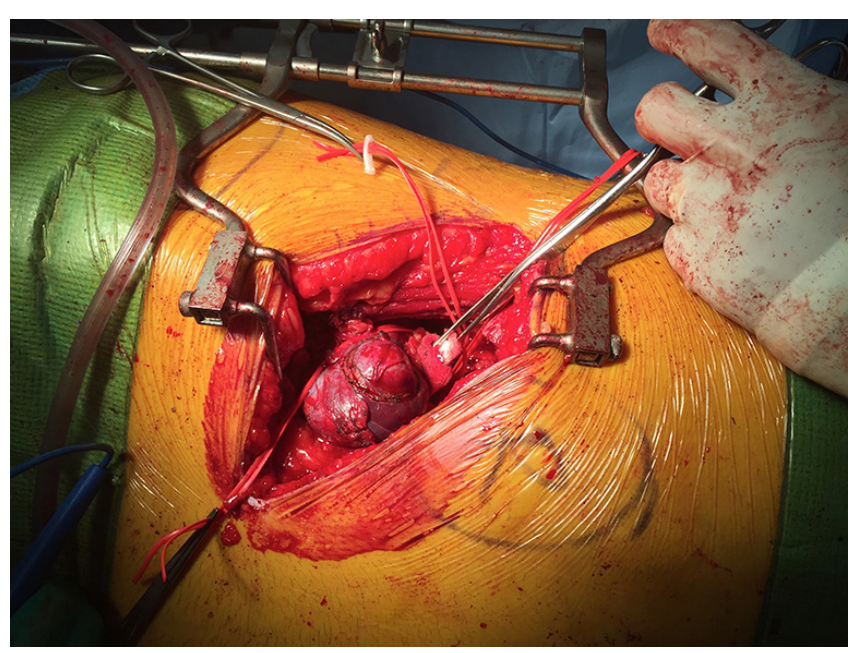

Figure 2 Intra-operative photo demonstrating exposure, retraction and vessel preparation prior to commencement of resection for RCC. RCC, renal cell carcinoma.

of avoiding ischemia-related renal injury entirely, the obvious counterbalance of bleeding risk is apparent (44).

A major advantage of OPN is the ability to safely and effectively minimize global renal ischemia by decreasing the core renal temperature. Intra-operative renal hypothermia and cold ischemia (CI) has the ability to prolong period of time for resection without compromising postoperative renal function. This technique has also been described in relation to robotic and laparoscopic $\mathrm{PN}$, although it is often cumbersome and technically difficult $(45,46)$. CI promotes renal hypometabolism and may cause a reduction of cell swelling and release of free radicals minimizing risk of long term renal injury (47). In cases where complex resection or prolonged repair is anticipated ( $>25$ minutes), CI is an invaluable technique to reduce risk of renal injury, aiming to decrease the core renal temperature to $15-20$ degrees Celsius $(48,49)$. The bottom of a bowel bag is split open and then the top of the bag with the tie is fit snuggly around the renal hilum still allowing access to the vessels for clamping. The renal artery (or artery and vein if necessary) is cross-clamped and ice slush placed in the bag and around the kidney. After 2-3 minutes, ice is cleared from the area of interest to create a window to the lesion and begin demarcating the resection margin. Following completion of the resection and repair, the ice is removed quickly and then the clamp removed.

Where time of resection is likely to be less than
20-25 minutes, CI is not necessary as there is no increased risk of acute or chronic renal injury and risk of permanent dialysis secondary to warm ischemia during this time (49). When compared to laparoscopic and robotic approaches, OPN has generally has a shorter warm ischemia time in published studies (50). With improved surgical expertise in robotic $\mathrm{PN}$ however, this is becoming more comparable. Interestingly, a large RCT is underway to assess the benefits of renal hypothermia in $\mathrm{PN}$ and this may well change practice (51).

Use of mannitol preconditioning is not recommended as studies have found it ineffective at preventing ischemia re-perfusion injury $(52,53)$. There is currently no drug, preconditioning or postconditioning agent that reliably protect the kidney against ischemia-reperfusion injury $(54,55)$.

\section{Resection}

The primary objective of resection is to remove the entire renal mass with negative margins, while preserving as much unaffected renal parenchyma as possible. Preoperative imaging paired with intraoperative ultrasound and palpation to define deep margins is important for successful removal of the mass. Sharp dissection of the capsule can be undertaken by blade or diathermy followed by use of tenotomy scissors to develop the deep margins of the specimen (Figure 2). Use of intra-operative cell salvage may be considered to conserve intra-operative blood loss and reduce blood transfusion rates (56).

Optimal oncologic control is gained where a normal tissue rim is removed with an undisrupted tumor. Reported margins offering oncological advantage are commonly quoted as $2-3 \mathrm{~mm}$ of normal tissue, although retrospective case studies with short term follow up have suggested $<1 \mathrm{~mm}$ can equally offer control as long as the margins are 'negative' $(57,58)$. Enucleation, or blunt dissection of the pseudocapsule surrounding the tumor is not advocated due to the risk of micro-invasion into normal renal parenchyma. While exophytic lesions often have easily defined peripheral borders, deep margins are more difficult to define as is the case for all margins in purely endophytic lesions. Intraoperative frozen section of margin biopsies may be required in some circumstances; however, utility is controversial as it may not always correlate with final margin status $(32,59)$. Positive surgical margin is an especially unwanted finding following PN regardless of technique with an incidence of $0-10 \%(60)$. This does not appear to differ significantly between open, laparoscopic and robotic PN. 
Table 5 Complications and risk following OPN

\begin{tabular}{lc}
\hline Complication & Risk (\%) $(14,38,65-68)$ \\
\hline Intra-operative & $1.2-5.26$ \\
Hemorrhage & $0.4-2.6$ \\
Damage to other organ (e.g., Spleen) & $5.1-11.5$ \\
Pleural injury & \\
Early post-operative & $2.4-5.4$ \\
AKI & $1.4-17$ \\
Urinary leak & $1.4-7.9$ \\
Hemorrhage & 12.5 \\
Chest infection/atelectasis & 12.7 \\
lleus & \\
Late post-operative & $1.4-17.4$ \\
Urinary fistula & $<1$ \\
Arteriovenous fistula & 0.6 \\
Hernia & $0.2-2.3$ \\
Death within 1 year & \\
\hline
\end{tabular}

OPN, open partial nephrectomy; AKI, acute kidney injury.

\section{Renorrbaphy}

Renorrhaphy aims to achieve watertight closure of the collecting system, hemostasis, and repair the renal defect while minimizing the effect on normal healthy vascularized parenchyma (61). Vessels on the cut surface of the kidney are identified and oversewn with absorbable sutures as required. Our preference is to use a barbed suture (e.g., 3-0 V-Loc ${ }^{\mathrm{TM}}$, Medtronic/Covidien ${ }^{\circledR}, \mathrm{MN}$, USA) as our hemostatic suture, running it along the cut surface of the kidney closing vessels and breaches in the collecting system. Advances in hemostatic products has allowed for less oversewing and can minimize ischemic time allowing for early unclamping. After unclamping and assessment for further bleeding vessels, we will perform a single layer renorrhaphy with single 0 -vicryl sutures secured at both ends with a clip (e.g., Hem-o-lok ${ }^{\circledR}$, Teleflex ${ }^{\circledR}$, NC, USA). We will occasionally use hemostatic agents for persistent ooze (e.g., Floseal ${ }^{\circledR}$ or TachoSil ${ }^{\circledR}$, Baxter Healthcare, IL, USA). We avoid Surgicel ${ }^{\circledR}$ bolsters (Johnson and Johnson, NJ, USA) in the renorrhaphy as these give the appearance of locules of gas in post-operative imaging. Single layer renorrhaphy has demonstrated improved renal functional outcomes compared with double layer renorrhaphy, although choice of interrupted or running suture closures have been equivocal (61). In cases where there is a breach of the collecting system leaving a postoperative drain should be considered to monitor for persistent urine leak. The routine use of a drain may be avoided with the aim of improving patient comfort without putting the operative outcome at risk (62).

\section{Extracorporeal renal surgery and autotransplantation}

Extracorporeal renal surgery with autotransplantation is a technique rarely used in contemporary urological surgery. Today, in even the most complex cases, PN can usually be performed without the added risk of autotransplantation. In cases of large or complex renal tumors in patients with solitary kidneys however, ex vivo resection and reconstruction incorporating the advances made in the transplant field with modern perfusates is considered the ultimate approach to nephron-sparing surgery. The excellent exposure, lighting and ability to cool in a completely bloodless surgical field provides an advantage in this technique, as well as the ability to avoid life-long hemodialysis. Recent evidence regarding this technique is limited to short case series. However, these series have demonstrated utility for this uncommon operation in maintaining renal function, quality of life and extending life expectancy (63).

\section{Post-operative issues}

Common complications following OPN include blood loss requiring transfusion, urinary fistula, and acute kidney injury (AKI) (16,64). Risk increases with tumor complexity and increased size. Table 5 outlines complications and risk associated with OPN. Post-operative bleeding is a time-critical complication that may require angiographic or surgical intervention. Bleeding can arise from either the kidney, renal hilum or adjacent structures. Early identification can be made by monitoring post-operative pain, vital signs, hemoglobin trends, and drain tube outputs (if utilised). If the patient experiences rapid clinical deterioration or has required blood transfusion of greater than two units, early consideration of angioembolization should be sought for control of potential segmental arterial bleeding (64). Uncommonly, delayed presentation of arteriovenous fistulas and renal artery pseudoaneurysms can present with hematuria, wound site bleeding or flank pain 
and are potentially life-threatening (69). This may also be managed with embolization (65).

The etiology of post-operative AKI following OPN is unclear, especially considering shorter or comparable ischemia time when compared to robotic PN (70). This suggests contributory effect of alternative perioperative variables experienced in OPN such as blood loss, contralateral renal function, and surgical technique. Short-term renal impairment following OPN is typically transient however, with return to a new steady state approximately 3 weeks postoperatively. Observational studies have demonstrated that most patient's renal function remain stable after this point with an $8.8 \%$ average loss over time (71).

Immediate urine leak following $\mathrm{PN}$ is recognized by moderate to high output of fluid in the drain, which should be confirmed biochemically with elevated creatinine or urea. Urine leak may also present insidiously 2-3 weeks post-operatively with the development of a fistula. Formal diagnosis of delayed or persistent urine leak is typically made by CT intravenous pyelogram (IVP) or retrograde pyelogram. Management involves decompression of the collecting system with a ureteric stent, urethral catheter and percutaneous drainage (66).

\section{Long-term outcomes}

Long-term functional and oncological outcomes following OPN is generally accepted as comparable to $\mathrm{RN}$ and minimally-invasive $\mathrm{PN}$ techniques. This is with exception of the Van Poppel et al. study which failed to show definitive oncological equivalence (14). However, this study was underpowered to show a definitive difference. With regard to higher complexity tumors, more recent literature is limited to cohort studies, and mostly find comparable results to RN (19). An OPN series comparing non-complex and complex renal masses by Bahouth et al. demonstrated excellent 10-year cancer specific survival (99\%) and no longterm change in renal function despite longer clamp time (26.5 and 28.9 minutes respectively) (72). There is limited evidence comparing OPN and robotic PN for complex tumors with most studies having difficulty matching cohorts for baseline tumor and patient characteristics. Although robotic PN appears superior in terms of intra-operative blood loss, hospital length of stay and transfusion rate, OPN provides comparable longer-term outcomes $(4,73,74)$. The paucity in evidence suggesting one surgical technique as superior over another in terms of functional and oncological outcomes is reflected in current guidelines.

\section{Conclusions}

OPN continues to have an important role in nephron-sparing surgery by allowing a safe and oncologically successful surgery in the setting of more complex renal tumors. As reflected in current guidelines, irrespective of surgical approach, treatment of small renal masses should focus on maximizing oncological and functional outcomes. Despite the growing expertise and technological advances when it comes to robotic PN techniques, OPN remains an important skill for an ever-diminishing proportion of renal masses.

\section{Acknowledgments}

Funding: None.

\section{Footnote}

Provenance and Peer Review: This article was commissioned by the Guest Editor (Shomik Sengupta) for the series "Surgery for Urologic Cancers" published in Translational Andrology and Urology. The article has undergone external peer review.

Conflicts of Interest: All authors have completed the ICMJE uniform disclosure form (available at http://dx. doi. org/10. 21037/tau-20-474). The series "Surgery for Urologic Cancers" was commissioned by the editorial office without any funding or sponsorship. The authors have no other conflicts of interest to declare.

Ethical Statement: The authors are accountable for all aspects of the work in ensuring that questions related to the accuracy or integrity of any part of the work are appropriately investigated and resolved.

Open Access Statement: This is an Open Access article distributed in accordance with the Creative Commons Attribution-NonCommercial-NoDerivs 4.0 International License (CC BY-NC-ND 4.0), which permits the noncommercial replication and distribution of the article with the strict proviso that no changes or edits are made and the original work is properly cited (including links to both the formal publication through the relevant DOI and the license). See: https://creativecommons.org/licenses/by-nc-nd/4.0/.

\section{References}

1. MacLennan S, Imamura M, Lapitan MC, et al. 
Systematic review of oncological outcomes following surgical management of localised renal cancer. Eur Urol 2012;61:972-93.

2. Herr HW. A history of partial nephrectomy for renal tumors. J Urol 2005;173:705-8.

3. Herr HW. Surgical management of renal tumors: a historical perspective. Urol Clin North Am 2008;35:543-9; v.

4. Hennessey DB, Wei G, Moon D, et al. Strategies for success: a multi-institutional study on robot-assisted partial nephrectomy for complex renal lesions. BJU Int 2018;121 Suppl 3:40-7.

5. Campbell S, Uzzo RG, Allaf ME, et al. Renal mass and localized renal cancer: AUA guideline. Linthicum: American Urological Association. 2017. Available online: https://www.auanet.org/guidelines/renal-cancer-renalmass-and-localized-renal-cancer-guideline. Accessed 05/12/2019.

6. Ljungberg B, Albiges L, Abu-Ghanem Y, et al. European Association of Urology guidelines on renal cell carcinoma: The 2019 Update. Eur Urol 2019;75:799-810.

7. Patel HD, Gupta M, Joice GA, et al. Clinical stage migration and survival for renal cell carcinoma in the United States. Eur Urol Oncol 2019;2:343-8.

8. DI Trapani E, Dell'oglio P, Larcher A, et al. Pathological high-risk renal cell carcinoma: trends in clinical characteristics over 25 years. Anticancer Res 2018;38: 4123-30.

9. Kane CJ, Mallin K, Ritchey J, et al. Renal cell cancer stage migration: analysis of the National Cancer Data Base. Cancer 2008;113:78-83.

10. Znaor A, Lortet-Tieulent J, Laversanne M, et al. International variations and trends in renal cell carcinoma incidence and mortality. Eur Urol 2015;67:519-30.

11. Saad AM, Gad MM, Al-Husseini MJ, et al. Trends in renal-cell carcinoma incidence and mortality in the United States in the last 2 decades: a SEER-based study. Clin Genitourin Cancer 2019;17:46-57.e5.

12. Capitanio U, Montorsi F. Renal cancer. Lancet 2016;387:894-906.

13. Thompson RH, Boorjian SA, Lohse CM, et al. Radical nephrectomy for $\mathrm{p}$ T1a renal masses may be associated with decreased overall survival compared with partial nephrectomy. J Urol 2008;179:468-71; discussion 472-3.

14. Van Poppel H, Da Pozzo L, Albrecht W, et al. A prospective, randomised EORTC intergroup phase 3 study comparing the oncologic outcome of elective nephronsparing surgery and radical nephrectomy for low-stage renal cell carcinoma. Eur Urol 2011;59:543-52.

15. Larcher A, Capitanio U, De Naeyer G, et al. Is robot-assisted surgery contraindicated in the case of partial nephrectomy for complex tumours or relevant comorbidities? A comparative analysis of morbidity, renal function, and oncologic outcomes. Eur Urol Oncol 2018;1:61-8.

16. Peyronnet B, Seisen T, Oger E, et al. Comparison of 1800 robotic and open partial nephrectomies for renal tumors. Ann Surg Oncol 2016;23:4277-83.

17. Bravi CA, Larcher A, Capitanio U, et al. Perioperative outcomes of open, laparoscopic, and robotic partial nephrectomy: a prospective multicenter observational study (the RECORd 2 project). Eur Urol Focus 2019. doi: 10.1016/j.euf.2019.10.013.

18. Ghali F, Elbakry AA, Hamilton ZA, et al. Robotic partial nephrectomy for clinical $\mathrm{T} 2 \mathrm{a}$ renal mass is associated with improved trifecta outcome compared to open partial nephrectomy: a single surgeon comparative analysis. World J Urol 2020;38:1113-22.

19. Kim JK, Lee H, Oh JJ, et al. Comparison of robotic and open partial nephrectomy for highly complex renal tumors (RENAL nephrometry score $\geq 10$ ). PLoS One 2019; 14:e0210413.

20. Liu NW, Khurana K, Sudarshan S, et al. Repeat partial nephrectomy on the solitary kidney: surgical, functional and oncological outcomes. J Urol 2010;183:1719-24.

21. Kutikov A, Uzzo RG. The R.E.N.A.L. nephrometry score: a comprehensive standardized system for quantitating renal tumor size, location and depth. J Urol 2009;182:844-53.

22. Ficarra V, Novara G, Secco S, et al. Preoperative aspects and dimensions used for an anatomical (PADUA) classification of renal tumours in patients who are candidates for nephron-sparing surgery. Eur Urol 2009;56:786-93.

23. Simmons MN, Ching CB, Samplaski MK, et al. Kidney tumor location measurement using the $\mathrm{C}$ index method. J Urol 2010;183:1708-13.

24. Manning TG, O'Brien JS, Christidis D, et al. Three dimensional models in uro-oncology: a future built with additive fabrication. World J Urol 2018;36:557-63.

25. Zheng Y, Espiritu P, Hakky T, et al. Predicting ease of perinephric fat dissection at time of open partial nephrectomy using preoperative fat density characteristics. BJU Int 2014;114:872-80.

26. Borregales LD, Adibi M, Thomas AZ, et al. Predicting adherent perinephric fat using preoperative clinical 
and radiological factors in patients undergoing partial nephrectomy. Eur Urol Focus 2019. doi: 10.1016/ j.euf.2019.10.007.

27. Johnson A, Sudarshan S, Liu J, et al. Feasibility and outcomes of repeat partial nephrectomy. J Urol 2008;180:89-93; discussion 93.

28. Bratslavsky G, Liu JJ, Johnson AD, et al. Salvage partial nephrectomy for hereditary renal cancer: feasibility and outcomes. J Urol 2008;179:67-70.

29. Lane BR, Demirjian S, Derweesh IH, et al. Survival and functional stability in chronic kidney disease due to surgical removal of nephrons: importance of the new baseline glomerular filtration rate. Eur Urol 2015;68:996-1003.

30. Richard PO, Lavallee LT, Pouliot F, et al. Is routine renal tumor biopsy associated with lower rates of benign histology following nephrectomy for small renal masses? J Urol 2018;200:731-6.

31. Patel HD, Nichols PE, Su ZT, et al. Renal mass biopsy is associated with reduction in surgery for early-stage kidney cancer. Urology 2020;135:76-81.

32. Kenney P, Wotkowicz C, Libertino J. Contemporary open surgery of the kidney. Campbell-Walsh Urology 2012;2:1612-3.

33. Kava BR. Partial nephrectomy. In: Whitehead ED. editor. Atlas of Surgical Techniques in Urology. Philadelphia: Lippincott-Raven, 1998:147-51.

34. Diblasio CJ, Snyder ME, Russo P. Mini-flank supra-11th rib incision for open partial or radical nephrectomy. BJU Int 2006;97:149-56.

35. Wang H, Zhou L, Guo J, et al. Mini-flank supra-12th rib incision for open partial nephrectomy compared with laparoscopic partial nephrectomy and traditional open partial nephrectomy. PLoS One 2014;9:e89155.

36. Caraballo ER, Palacios DA, Suk-Ouichai C, et al. Open partial nephrectomy when a non-flank approach is required: indications and outcomes. World Journal of Urology 2019;37:515-22.

37. Chatterjee S, Nam R, Fleshner N, et al. Permanent flank bulge is a consequence of flank incision for radical nephrectomy in one half of patients. Urol Oncol 2004;22:36-9.

38. Anastasiadis E, O'Brien T, Fernando A. Open partial nephrectomy in renal cell cancer-Essential or obsolete? Int J Surg 2016;36:541-7.

39. Russo P. Open partial nephrectomy. Personal technique and current outcomes. Arch Esp Urol 2011;64:571-93.

40. Novick AC, Derweesh I. Open partial nephrectomy for renal tumours: current status. BJU Int 2005;95 Suppl 2:35-40.

41. Zhang L, Wu B, Zha Z, et al. Comparison of selective and main renal artery clamping in partial nephrectomy of renal cell cancer: a PRISMA-compliant systematic review and meta-analysis. Medicine (Baltimore) 2018;97:e11856.

42. Paulucci DJ, Rosen DC, Sfakianos JP, et al. Selective arterial clamping does not improve outcomes in robotassisted partial nephrectomy: a propensity-score analysis of patients without impaired renal function. BJU Int 2017;119:430-5.

43. Hsi RS, Macleod LC, Gore JL, et al. Comparison of selective parenchymal clamping to hilar clamping during robotic-assisted laparoscopic partial nephrectomy. Urology 2014;83:339-44.

44. Simone G, Gill IS, Mottrie A, et al. Indications, techniques, outcomes, and limitations for minimally ischemic and offclamp partial nephrectomy: a systematic review of the literature. European Urology 2015;68:632-40.

45. Ramirez D, Caputo PA, Krishnan J, et al. Robot-assisted partial nephrectomy with intracorporeal renal hypothermia using ice slush: step-by-step technique and matched comparison with warm ischaemia. BJU Int 2016;117:531-6.

46. Ramani AP, Ryndin I, Lynch AC, et al. Current concepts in achieving renal hypothermia during laparoscopic partial nephrectomy. BJU Int 2006;97:342-4.

47. Becker F, Van Poppel H, Hakenberg OW, et al. Assessing the impact of ischaemia time during partial nephrectomy. Eur Urol 2009;56:625-34.

48. Volpe A, Blute ML, Ficarra V, et al. Renal ischemia and function after partial nephrectomy: a collaborative review of the literature. European Urology 2015;68:61-74.

49. Lane BR, Gill IS, Fergany AF, et al. Limited warm ischemia during elective partial nephrectomy has only a marginal impact on renal functional outcomes. J Urol 2011;185:1598-603.

50. Seveso M, Grizzi F, Bozzini G, et al. Open partial nephrectomy: ancient art or currently available technique? Int Urol Nephrol 2015;47:1923-32.

51. Breau RH, Cagiannos I, Knoll G, et al. Renal hypothermia during partial nephrectomy for patients with renal tumours: a randomised controlled clinical trial protocol. BMJ Open 2019;9:e025662.

52. Choi K, Hill S, Hale N, et al. Intraoperative mannitol during robotic-assisted-laparoscopic partial nephrectomy. J Robot Surg 2019;13:401-5.

53. Spaliviero M, Power NE, Murray KS, et al. Intravenous mannitol versus placebo during partial nephrectomy 
in patients with normal kidney function: a doubleblind, clinically-integrated, randomized trial. Eur Urol 2018;73:53-9.

54. Zacharias M, Mugawar M, Herbison GP, et al. Interventions for protecting renal function in the perioperative period. Cochrane Database Syst Rev 2008;(4):CD003590.

55. O'Kane D, Baldwin GS, Bolton DM, et al. Preconditioning against renal ischaemia reperfusion injury: the failure to translate to the clinic. J Nephrol 2019;32:539-47.

56. Kinnear N, O'Callaghan M, Hennessey D, et al. Intraoperative cell salvage in urological surgery: a systematic review and meta-analysis of comparative studies. BJU Int 2019;123:210-9.

57. Marszalek M, Carini M, Chlosta P, et al. Positive surgical margins after nephron-sparing surgery. Eur Urol 2012;61:757-63.

58. Castilla EA, Liou LS, Abrahams NA, et al. Prognostic importance of resection margin width after nephronsparing surgery for renal cell carcinoma. Urology 2002;60:993-7.

59. Sterious SN, Simhan J, Smaldone MC, et al. Is there a benefit to frozen section analysis at the time of partial nephrectomy? Can J Urol 2013;20:6778-84.

60. Zhang L, Wu B, Zha Z, et al. The correlation of clinicopathological features with the status of surgical margins in renal cell cancer patients following nephronsparing surgery: a systematic review and meta-analysis. Front Oncol 2019;9:648.

61. Bertolo R, Campi R, Mir MC, et al. Systematic review and pooled analysis of the impact of renorrhaphy techniques on renal functional outcome after partial nephrectomy. Eur Urol Oncol 2019;2:572-5.

62. Godoy G, Katz DJ, Adamy A, et al. Routine drain placement after partial nephrectomy is not always necessary. J Urol 2011;186:411-5.

63. Janssen MWW, Linxweiler J, Philipps I, et al. Kidney autotransplantation after nephrectomy and work bench surgery as an ultimate approach to nephron-sparing surgery. World J Surg Oncol 2018;16:35.

64. Tay KJ, Rampersaud EN, Inman BA. Open Partial Nephrectomy. In: Smith JA, Howards SS, Preminger

Cite this article as: O'Connor E, Timm B, Lawrentschuk N, Ischia J. Open partial nephrectomy: current review. Transl Androl Urol 2020;9(6):3149-3159. doi: 10.21037/tau-20-474
GM, et al. Hinman's Atlas of Urologic Surgery. 4th ed. Philadelphia: Elsevier, 2018:76-81.

65. Heye S, Maleux G, Van Poppel H, et al. Hemorrhagic complications after nephron-sparing surgery: angiographic diagnosis and management by transcatheter embolization. AJR Am J Roentgenol 2005;184:1661-4.

66. Erlich T, Abu-Ghanem Y, Ramon J, et al. Postoperative urinary leakage following partial nephrectomy for renal mass: risk factors and a proposed algorithm for the diagnosis and management. Scand J Surg 2017;106:139-44.

67. Springer C, Hoda MR, Fajkovic H, et al. Laparoscopic vs open partial nephrectomy for T1 renal tumours: evaluation of long-term oncological and functional outcomes in 340 patients. BJU Int 2013;111:281-8.

68. Gratzke C, Seitz M, Bayrle F, et al. Quality of life and perioperative outcomes after retroperitoneoscopic radical nephrectomy $(\mathrm{RN})$, open $\mathrm{RN}$ and nephron-sparing surgery in patients with renal cell carcinoma. BJU Int 2009; 104:470-5.

69. Nouhaud FX, Williams M, Arnfield E, et al. Is postoperative Doppler ultrasonography useful for the early detection of asymptomatic pseudoaneurysm and prevention of haemorrhagic complications after partial nephrectomy? BJU Int 2018;122 Suppl 5:15-21.

70. Tsai SH, Tseng PT, Sherer BA, et al. Open versus robotic partial nephrectomy: Systematic review and meta-analysis of contemporary studies. Int J Med Robot 2019;15:e1963.

71. Lane BR, Babineau DC, Poggio ED, et al. Factors predicting renal functional outcome after partial nephrectomy. J Urol 2008;180:2363-8; discussion 2368-9.

72. Bahouth Z, Halachmi S, Getzler I, et al. Functional and oncological outcomes of open nephron-sparing surgery for complex renal masses. Urol Oncol 2015;33:427.e11-6.

73. Xia L, Wang X, Xu T, et al. Systematic review and metaanalysis of comparative studies reporting perioperative outcomes of robot-assisted partial nephrectomy versus open partial nephrectomy. J Endourol 2017;31:893-909.

74. Garisto J, Bertolo R, Dagenais J, et al. Robotic versus open partial nephrectomy for highly complex renal masses: comparison of perioperative, functional, and oncological outcomes. Urol Oncol 2018;36:471.e1-9. 